\title{
Experimental and Numerical Study of Huff-n-Puff Gas Injection to Re-vaporize Liquid Dropout in Shale Gas Condensate Reservoirs
}

\author{
Xingbang Meng ${ }^{1}$ and James J. Sheng ${ }^{1,2 *}$ \\ 1. Texas Tech University \\ 2. Southwest Petroleum University \\ *Corresponding author, james.sheng@,ttu.edu, phone: 8068348477
}

\begin{abstract}
The complex flow behavior of a gas condensate reservoir is caused by the compositional changes and the creation of condensate blockage around the wellbore. Once the pressure is lower than the dew point pressure, liquid dropout is formed in the reservoir. This liquid dropout reduces gas relative permeability. As a consequence, gas production is decreased and liquid dropout-condensate, a valuable resource, remains in the reservoir.

Huff-n-puff gas injection has been shown to be an effective approach for enhancing condensate recovery in shale gas condensate reservoirs (Sheng, 2015; Meng and Sheng, 2015). In this paper, the revaporization mechanism of huff-n-puff gas injection is investigated from both experimental and numerical work. In huff-n-puff gas injection, when pressure is increasedto be higher than the dew point pressure, part of the condensate can be re-vaporized and flows to the production well with gas during the puff process. Since there is only one well in the huff-n-puff process, the condensate region is near the well. When gas is injected into the reservoir, the pressure of the condensate region will be increased rapidly. Very limited research has been conducted on the re-vaporization of condensate, especially for shale gas condensate reservoir.

Both experimental work and simulation study have confirmed the mechanism of condensate revaporization by huff-n-puff gas injection. The work from this paper indicates that huff-n-puff is an effective way to re-vaporize the condensate and enhance the condensate recovery.
\end{abstract}

\section{Introduction}

Duringgas condensate reservoir production, liquid condensation and subsequent accumulation occur in the near-wellbore region when the pressure falls below the dewpoint pressure. Also, the accumulation of condensatereduces gas relative permeability and decreases well deliverability. Moreover, the liquid condensate is composed of heavy components of reservoir fluid whichhavea good economic value in the industry. Thus, developingthe methods to enhance condensate recovery in shale gas condensate reservoirs is important.

Up to now, there are a few researches for the mitigation of condensate blockage in shale gas condensate reservoirs, but more research has been conducted in conventional gas condensate reservoirs. Basically, there are two main types of approaches to reduce the condensation in formation. The first one is to reduce pressure drawdown to maintain the pressure above the dew point. Another one is to change the phase behavior of gas-condensate fluid to reduce the condensate blockage. For the second approach, some chemical methods have been studied (Al-Anazi et al., 2002; Al-Anazi et al., 2005; Zheng and Rao, 2010; Zheng and Rao, 2011; Bang et al., 2008; Bang et al., 2009; Du et al., 2000; Kumar et al., 2006). 
Gas injection is applied to maintain the reservoir higher than the dew point pressure. One way is to inject the gas when the pressure is still higher than the dew point pressure, it could maintain the pressure higher than the dew point, preventing the formation of condensate (Abel et al., 1970; Luo et al., 2001). Another is to inject gas when the pressure is depleted lower than the dew point pressure. After the injection, the pressure could be increased and the condensate blockage could be reduced (Luo et al., 2001). Different gas injection methods have been used and differenttypes of gas has been injected in conventional gas condensate reservoirs (Amini et al., 2011; Sanger and Hagoort, 1998). The studies show that gas injection can effectively enhance condensate recovery in conventional gas condensate reservoirs.

In this paper, the efficiency of huff-n-puff gas injection on shale cores was investigated experimentally. Then the re-vaporization mechanism of huff-n-puff gas injection to enhance condensate recovery was studied both experimentally and numerically.

\section{Experimental}

\subsection{Material Preparation}

An Eagle Ford core with 1.5-in in diameter and 2-in in length was used in the experiment. Table 1 shows the properties of the core.

Table 1:

Core properties

\begin{tabular}{ccc}
\hline & Value & Unit \\
\hline Length & 2 & Inch \\
Diameter & 1.5 & Inch \\
Porosity & 6.8 & $\%$ \\
Permeability & 0.0001 & $\mathrm{md}$ \\
\hline
\end{tabular}

A synthetic gas condensate mixture was used during the experiment. The gas mixture was composed of $85 \%$ methane and $15 \%$ n-butane. Fig. 1 shows the phase envelope for this binary gas condensate mixture and Fig. 2 shows the liquid dropout curve at $68^{\circ} \mathrm{F}$. As the pressure decreases lower than the dew point pressure, liquid phase is formed and continues accumulation to a maximum volume. From Fig. 1 and Fig 2, it can be seen than when the pressure is increased to higher than the dew point pressure, the liquid can be re-vaporized and becomes gaseous again. 


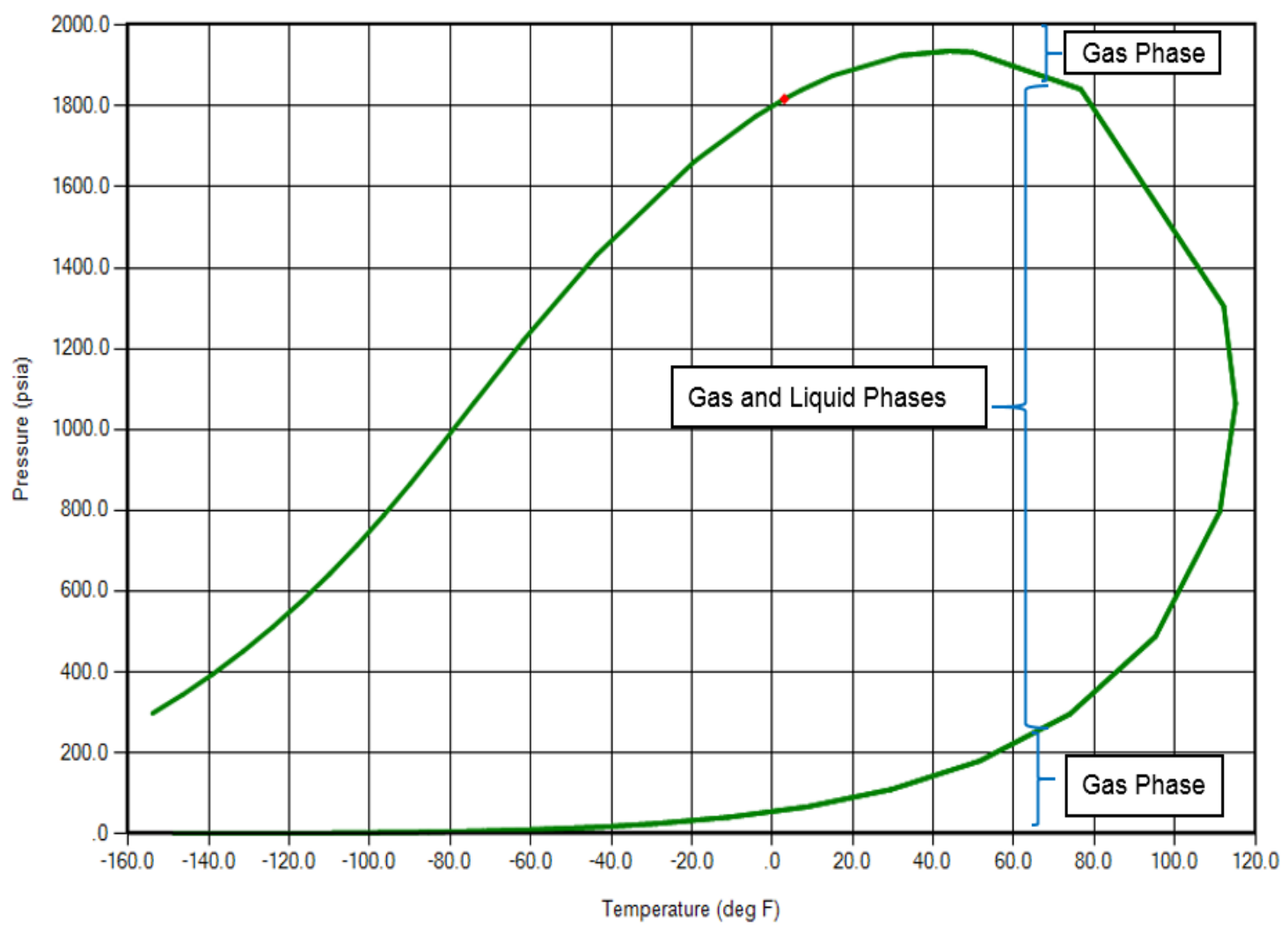

Fig. 1: Phase diagram of gas condensate mixture used in the experiment

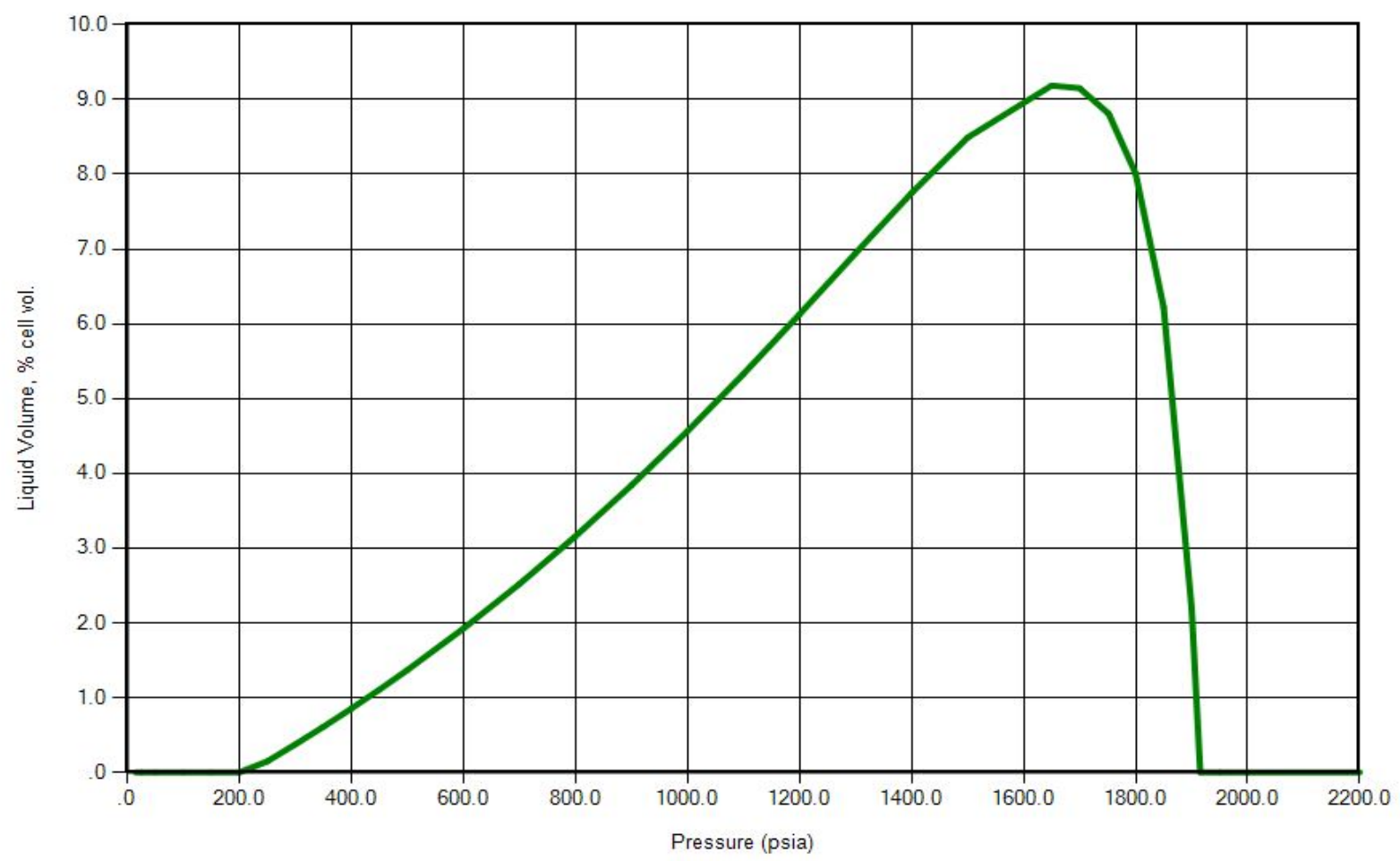

Fig.2: Liquid dropout curve of gas mixture, $68^{\circ} \mathrm{F}$ 


\subsection{Huff-n-puff Procedure}

A schematic of huff-n-puff gas injection apparatus is shown in Fig.3. The experiment was designed at the room temperature $68{ }^{\circ} \mathrm{F}$ based on the phase envelop of the gas condensate mixture. The core holder was used as a vessel in the experiment. Anoverburden pressureof 2500 psi was added around the core. The gas condensate mixture was first prepared in the accumulator at 2200 psi which was higher than the dew point pressure. A pump was used to maintain the pressure of the accumulator at 2200 psi. During the saturating process, CT scanner was used to measure the change of the core CT number. When the CT number was not changing any more, the core was fully saturated. After that, a primary depletion was conducted. Two depletion stages were set: 2200 psi to 1850 psi, 1850 psi to 1500 psi. The produced gas samples were collected by vacuumed air bags.

After the primary depletion, huff-n-puff gas injection was applied. The methane was injected into the core at 2000 psi for 2 hours. After that, the pressure of the core holder was depleted to 1500 psi. The produced gas was also collected by a vacuumed air bag. This completedwas one cycle of huff-n-puff gas injection. Five cycles were conducted.

The CT scanner was used to determine the core CT number after every puff process. AGC-MS instrument was used to analyze the compositions of produced gas samples.

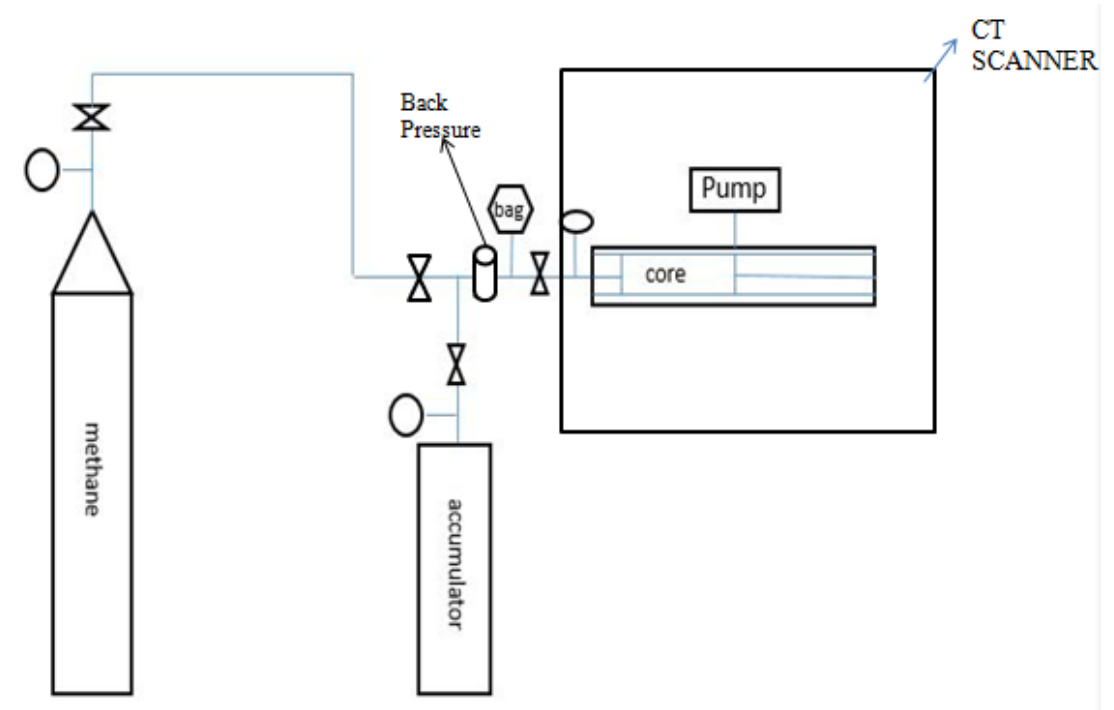

Fig.3: Schematic of huff-n-puff gas injection

\section{Simulation Model}

A basic Cartesian model was built to simulate the experiment process to investigate the revaporization mechanism of huff-n-puff gas injection to enhance the condensate recovery. The model was built to simulate the application of huff-n-puff gas injection in the core, as shown in Fig.4. The grid blocks of the simulation model were $66 \times 1 \times 11$. The initial fluid in the model was composed of methane $(85 \%)$ and butane $(15 \%)$. The production well and injection well were perforated at the same position because in a huff-n-puff process, the injection well and the production well were the same well. The injection well was constraint to inject at a maximum injection pressure of 2000 psi and the production 
well was subjected toa minimum bottom-hole pressure of 1500 psi. The permeability of the matrix in the model was $0.0001 \mathrm{md}$ and the porosity was $6.8 \%$. Table 2 shows the reservoir rock and fluid properties in this simulation model.
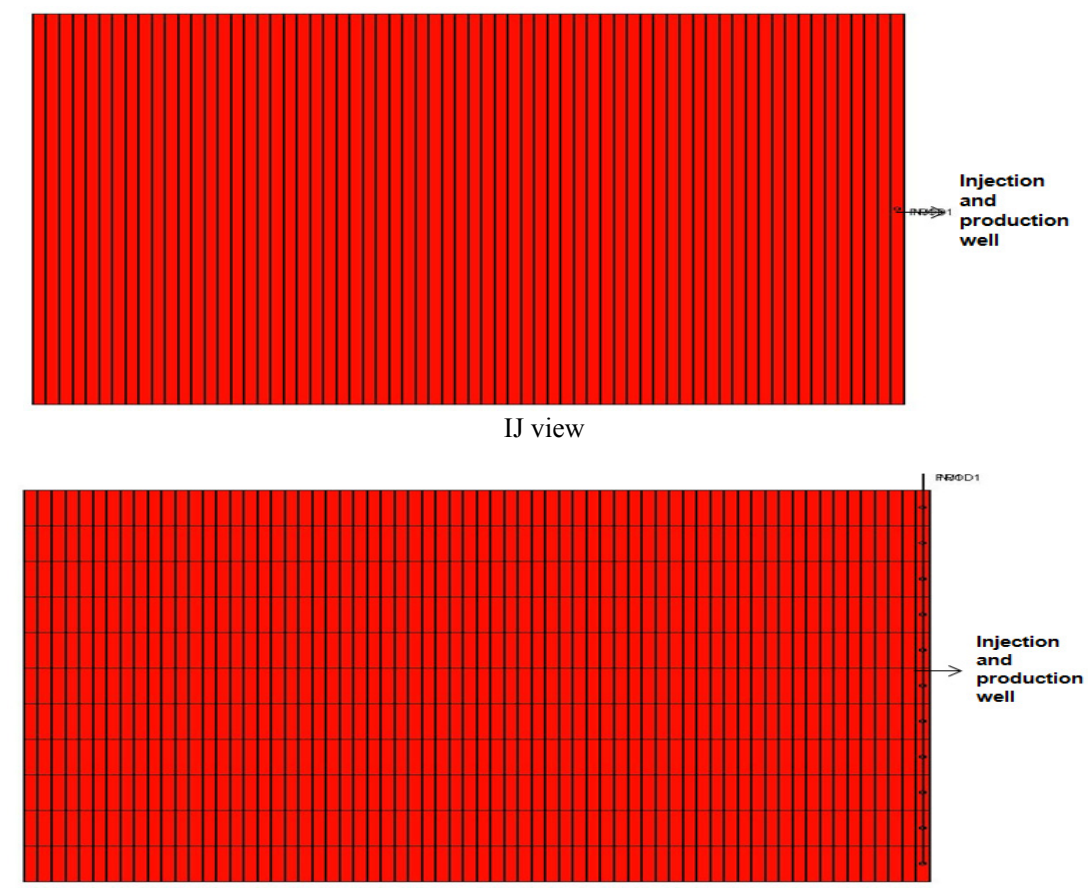

IK View

Fig.4: Simulation model of huff-n-puff, IJ view and JK view

Table 2:

Reservoir and fluid properties used in the simulation

\begin{tabular}{lll}
\hline Parameters & Value & Unit \\
\hline Initial core pressure & 2500 & $\mathrm{psi}$ \\
Injecting pressure & 2000 & $\mathrm{psi}$ \\
Producing pressure & 1500 & $\mathrm{psi}$ \\
Reservoir temperature & 68 & ${ }^{\circ} \mathrm{F}$ \\
Porosity of matrix & $6.8 \%$ & value \\
Permeability of Matrix & 0.0001 & $\mathrm{md}$ \\
\hline
\end{tabular}

\section{Results and Discussion}

In our experiment, the condensate saturation of the core was determined by the CT number by applying the Equation 1 below (Vo, 2010). CTexp is the CT number of the core containing both liquid and gas phases in the experiment when the pressure is depleted. CTgr is the CT number of the core when it is only saturated with methane, and CTcr is the CT number of the core when it is only saturated with nbutane. 


$$
\mathrm{Sc}=\frac{C T \exp -C T g r}{C T C r-C T g r}(\text { Equation 1) }
$$

A CT scanner was used to determine the CT numbers of the core after primary depletion and every puff process. After the primary depletion, the pressure was lower than the dew point pressure and the condensate was formed in the core. A primary condensate saturation would be attained. After the application of every cycle of huff-n-puff gas injection, the condensate saturation of the core was determined again. By comparing the condensate saturation, the condensate recovery could be determined. Fig. 5 shows the variation of the condensate saturation.Fig. 6 shows the condensate recovery by applying huff-n-puff gas injection. Reduction of the condensate saturation indicates that the condensate was produced from the core. However, understanding the way condensate produced is an important issue for the application of huff-n-puff gas injection in reservoir.

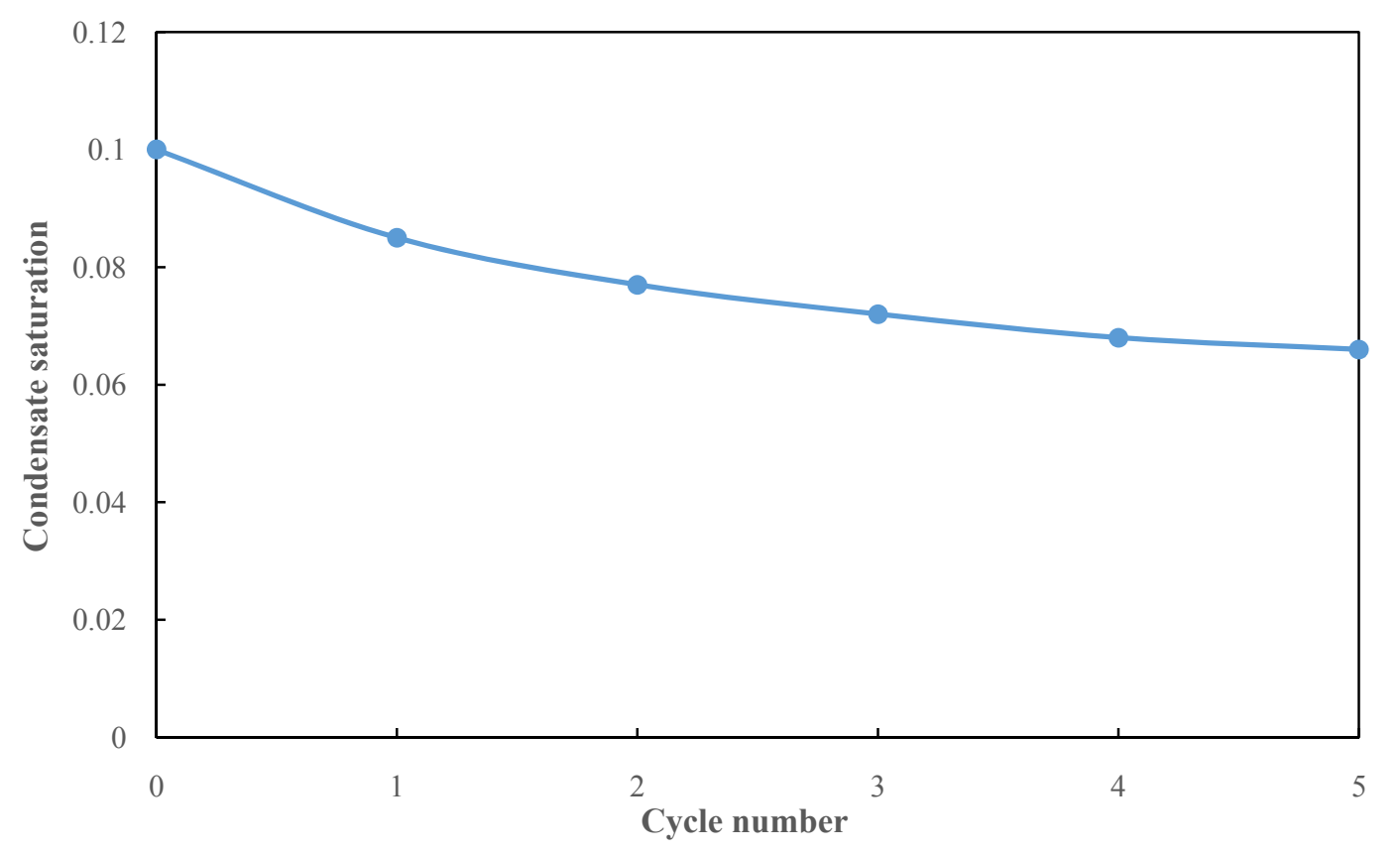

Fig.5: Variation of condensate saturation 


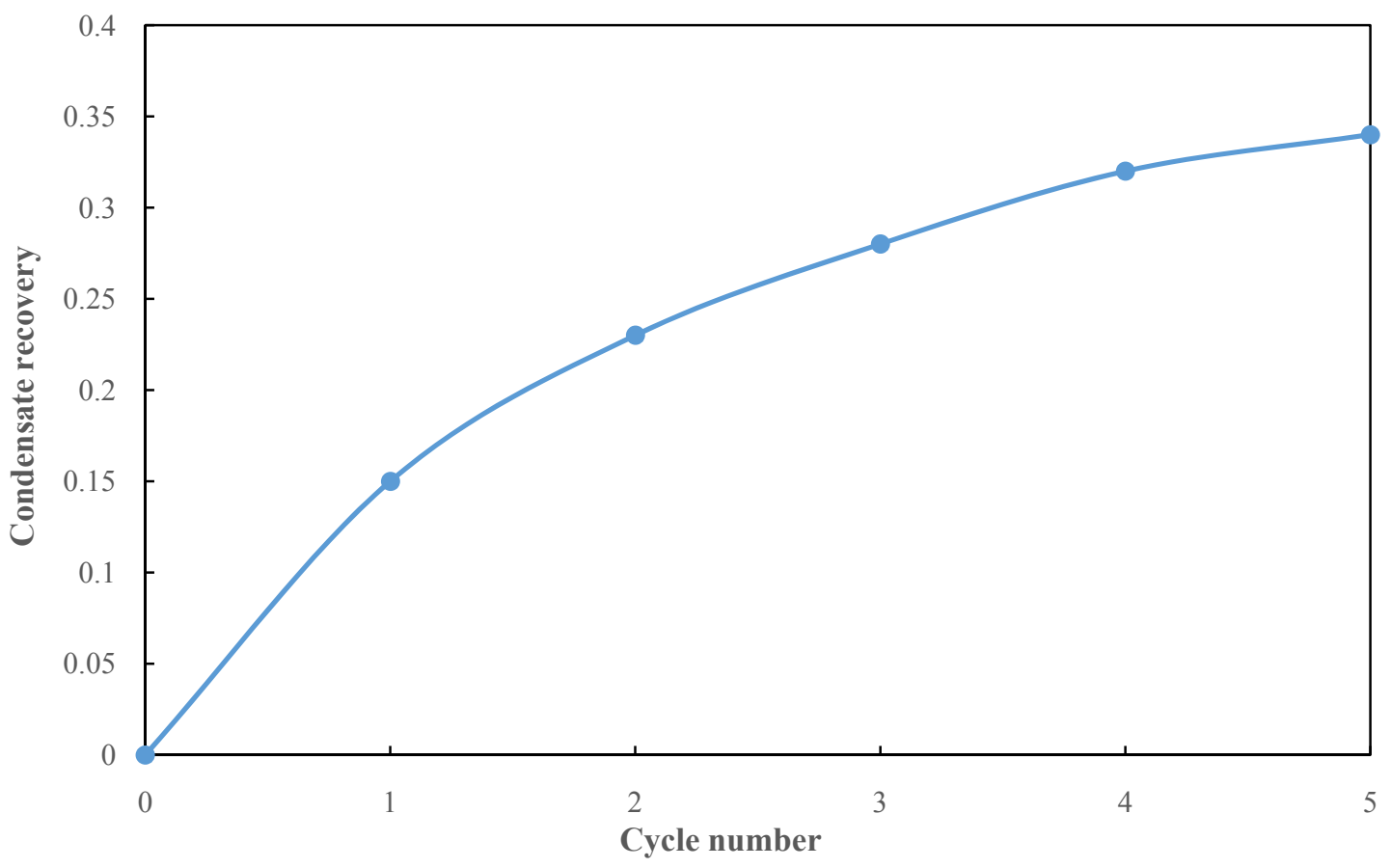

Fig.6: Variation of condensate recovery

The compositions of produced gas samples were measured by a gas chromatography (GC) instrument. Table 3 shows the butane content in produced gas at different periods. Fig. 7 shows butane content variation during the primary depletion. As Fig.7illustrates, produced butane was reduced. In the beginning, the pressure was higher than the dew point pressure, the produced gas contained high content of butane. Once the pressure was lower than the dew point pressure, butane was formed as liquid and remained in the core. Thus, the butane content in produced gas was reduced.

Table 3:

Butane $\%$ in produced gas

\begin{tabular}{cc}
\hline Stage & $\%$ \\
\hline Initial production & 12.04 \\
After 40 minutes primary depletion & 4 \\
End of primary depletion & 2 \\
$1^{\text {st }}$ cycle & 10.7 \\
$2^{\text {nd }}$ cycle & 8.7 \\
$3^{\text {rd }}$ cycle & 5.53 \\
$4^{\text {th }}$ cycle & 5.4 \\
$5^{\text {th }}$ cycle & 5.185 \\
\hline
\end{tabular}




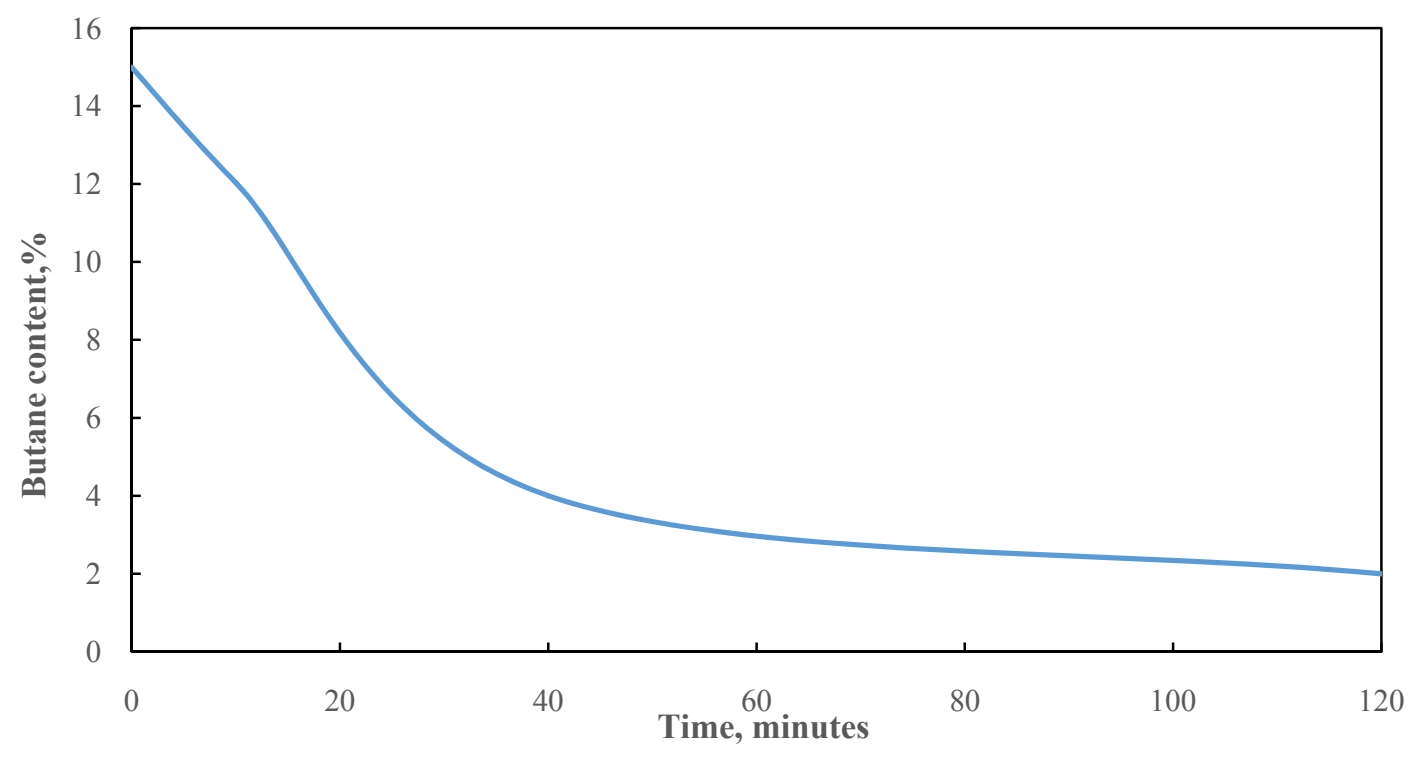

Fig.7: Butane content during primary depletion in experiment

When huff-n-puff gas injection was applied in the experiment, the butane content in produced gas was increased as shown in Fig.8. Butane content in produced gas which was collected at the end of primary depletion was $2 \%$. However, after the 1 st cycle of huff-n-puff gas injection, the butane content was increased to $10 \%$. More butane was produced from the core in gas state. This incremental of butane in gas state in Fig.8indicates the re-vaporization mechanism of huff-n-puff gas injectionexperimentally. During the huff process in the experiment, the pressure of the core was increased to be higher than the dew point pressure, liquid condensate was re-vaporized into gas. Hence, in the puff period, condensate was produced together with methane in gas state.

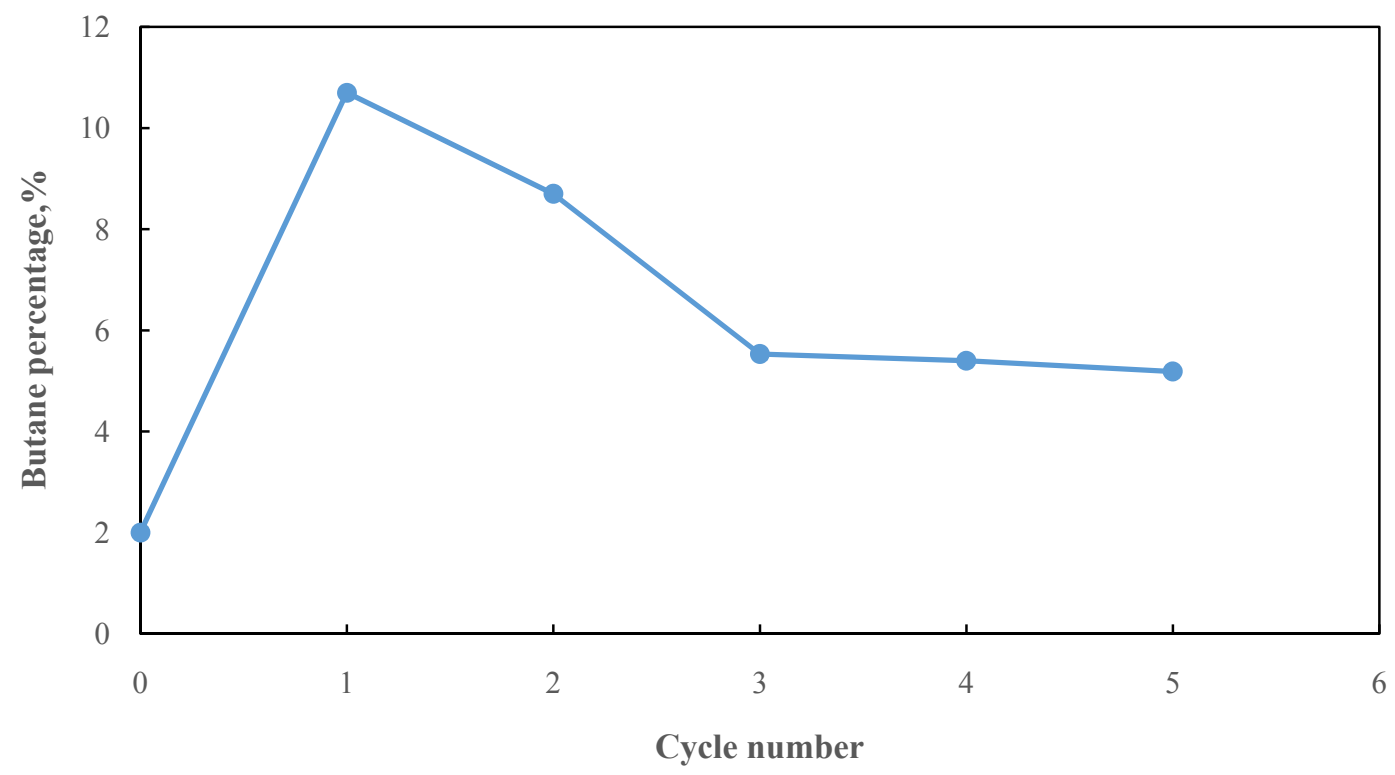

Fig.8: Butane content after primary depletion and huff-n-puff cycles in experiment 
The simulation of this experiment also proves the re-vaporization mechanism of huff-n-puff gas injection. Fig.9shows that using $66 \times 1 \times 11$ grid blocks produced similar results of those with more refined $100 \times 1 \times 11$ grid blocks. Fig. 10 and Fig. 11 show the simulation results of condensate saturation and condensate recovery by huff-n-puff gas injection. Oil saturation in Fig. 10is the condensate saturation because there was no liquid in the modelin the initial condition.

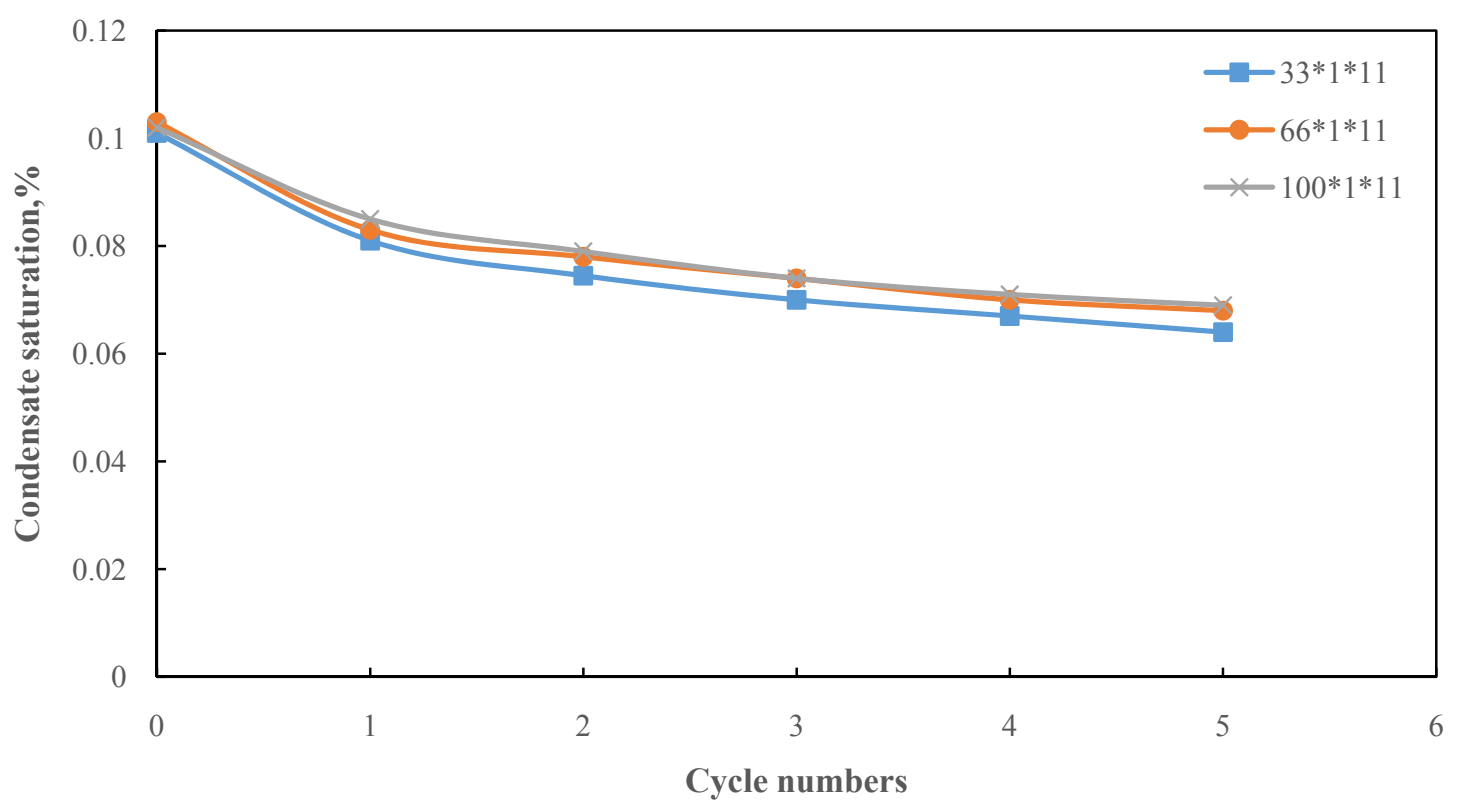

Fig. 9: Effect of numerical dispersion on the change of condensate saturation

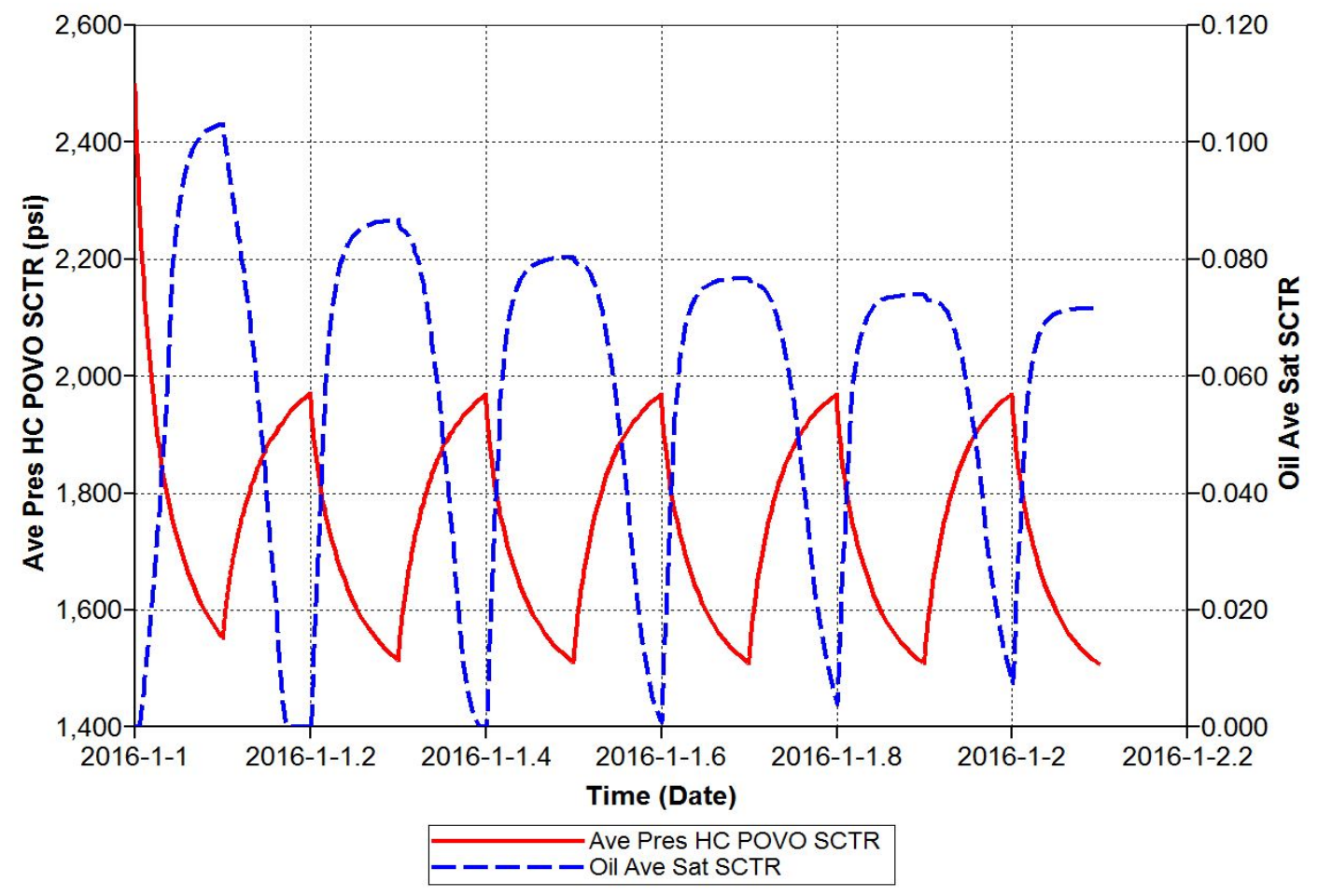

Fig. 10: Pressure and condensate saturation in simulation 


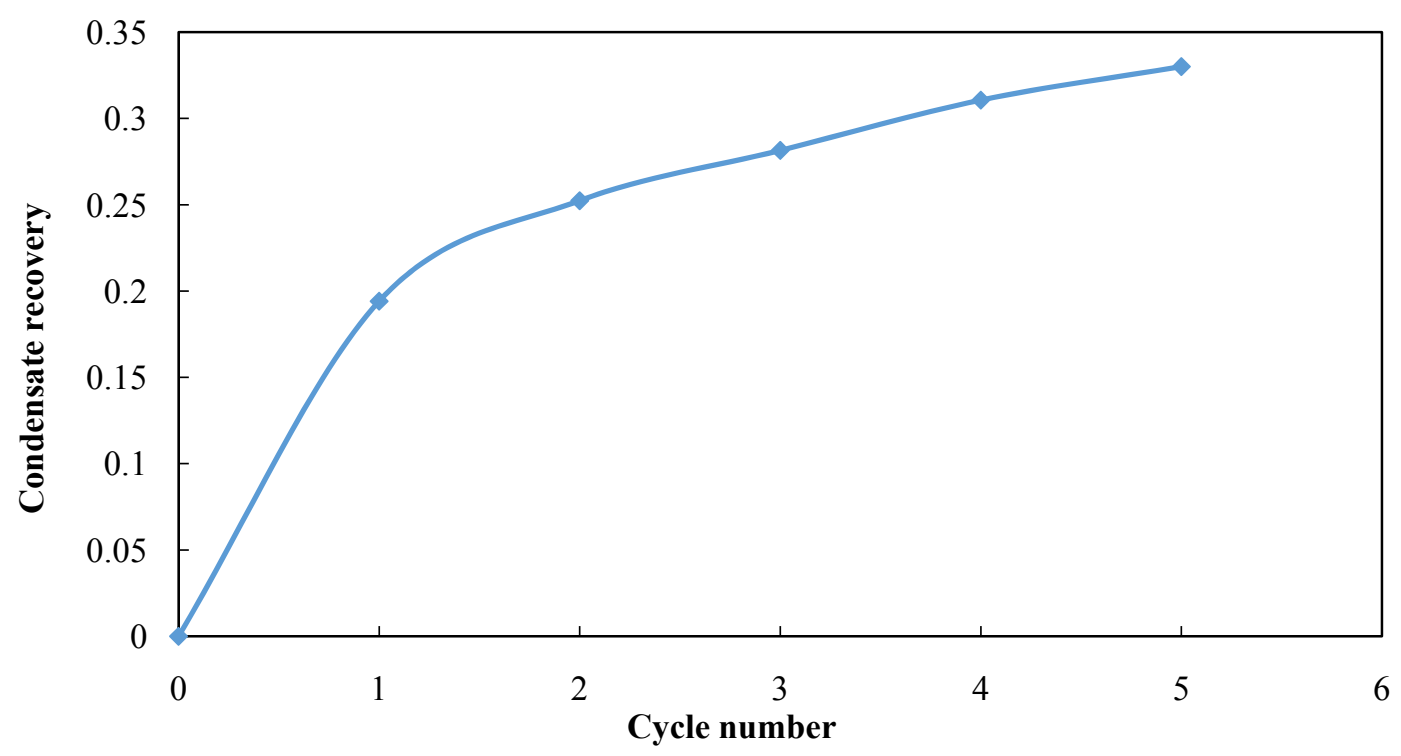

Fig. 11: Condensate recovery in simulation

From Fig. 10 it can be seen that as the pressure was depleted lower than the dew point pressure, condensate was formed and condensate saturation was increased. After applying huff-n-puff gas injection, the condensate saturation was reduced. Reduction of the condensate saturation indicates that the condensate was produced from the core. Fig. 12 shows the change of condensate saturation in a specific block (50 1 5). This block was near the wellbore. After the first cycle, the condensate saturation was a little bit increased because the condensate in the blocks away from the well was re-vaporized to gas and flowed into the block ( 5015 ). When the pressure was depleted, the re-vaporized condensate was formed as liquid again in the block (50 1 5). In the later cycles, condensate saturation was reduced because the condensate in this block was re-vaporized into gas state and produced from the core.

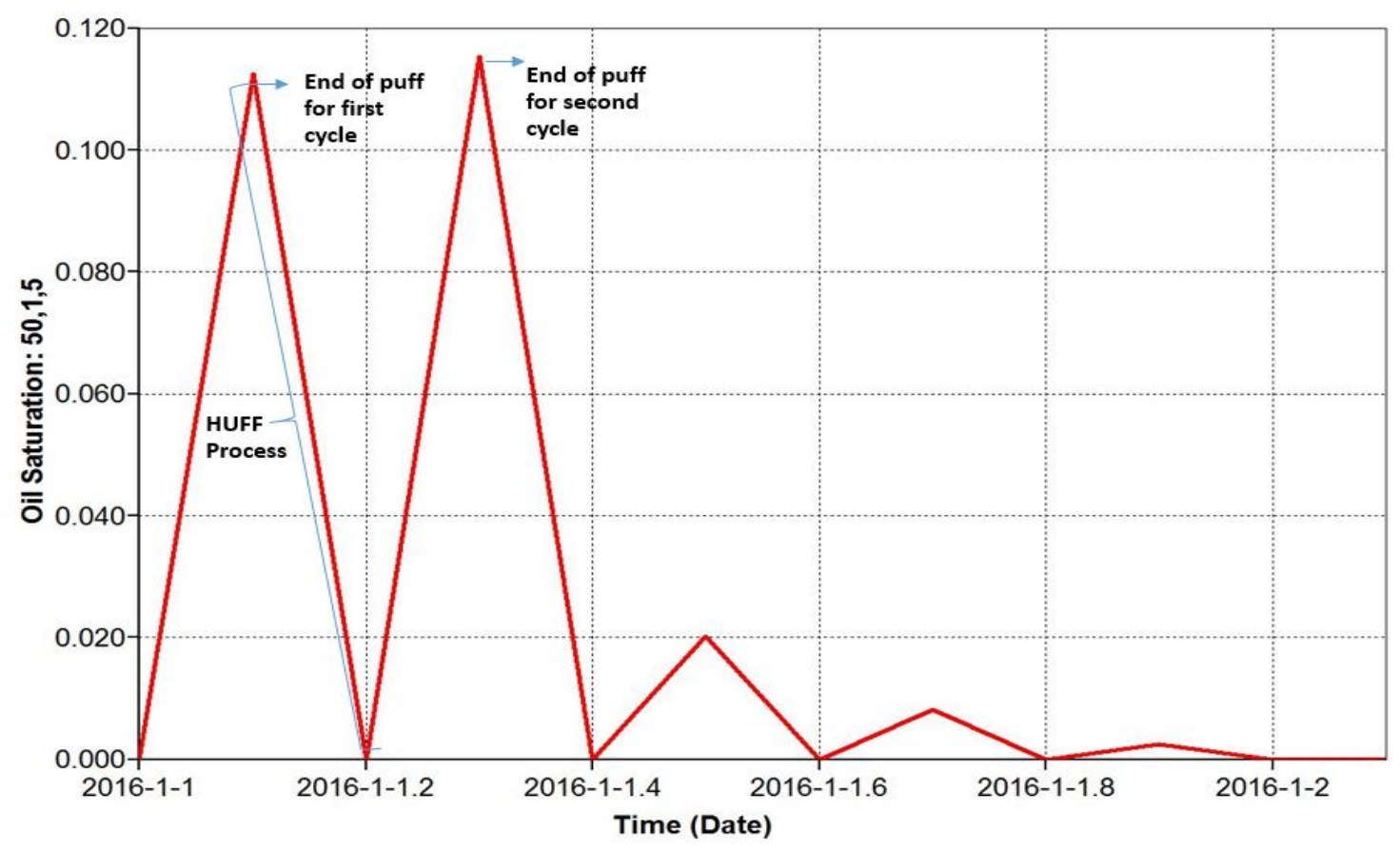


Fig. 12: Condensate saturation in block $(50,1,5)$

Fig. 13 and Fig. 14 shows the history matches for condensate recovery and butane content in the produced gas. It is demonstrated thatboth the condensate saturation and butane content measured by experiment are matched by their respective data from simulation.

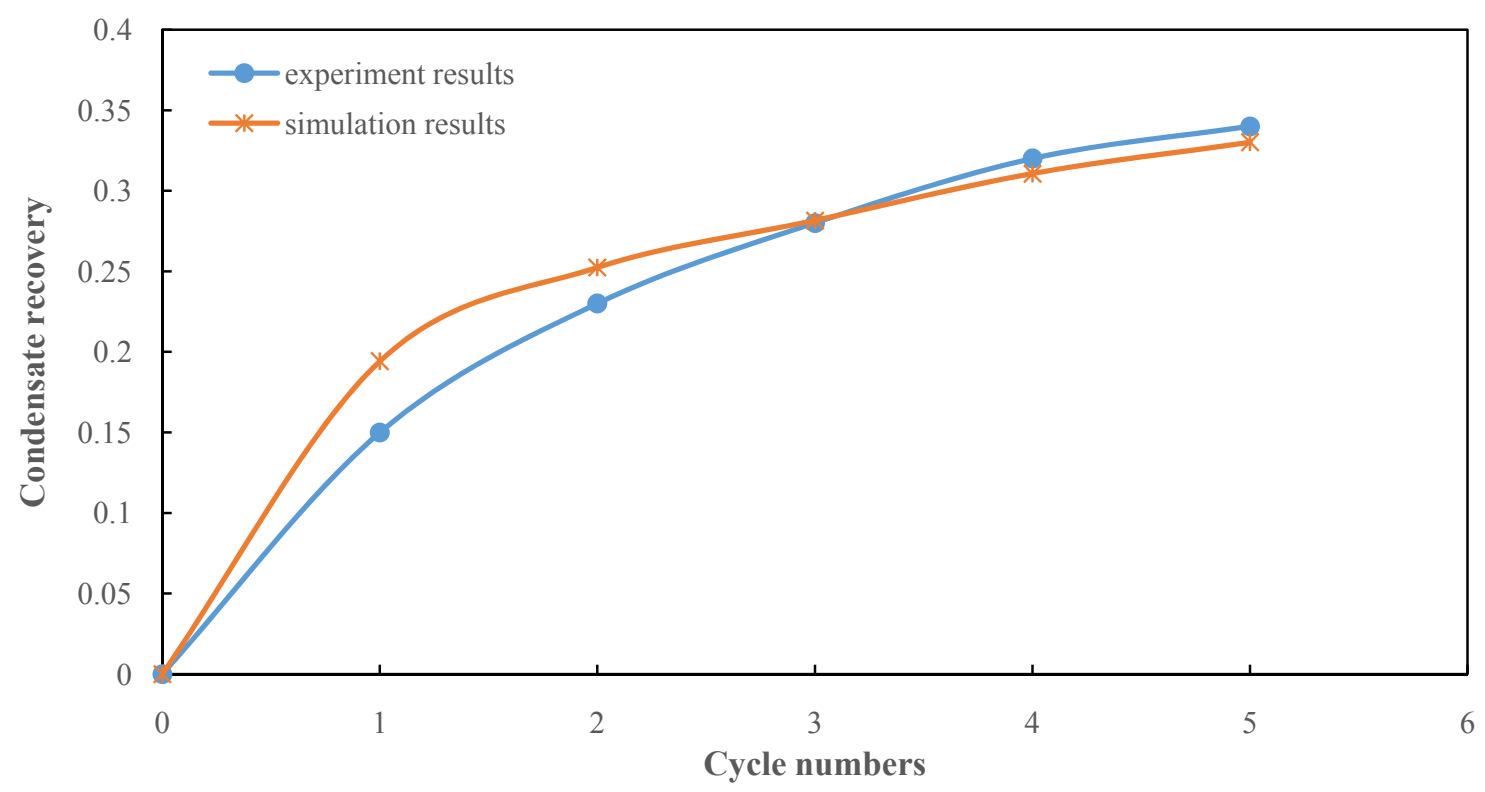

Fig. 13: Condensate recovery comparison of simulation results with experimental data

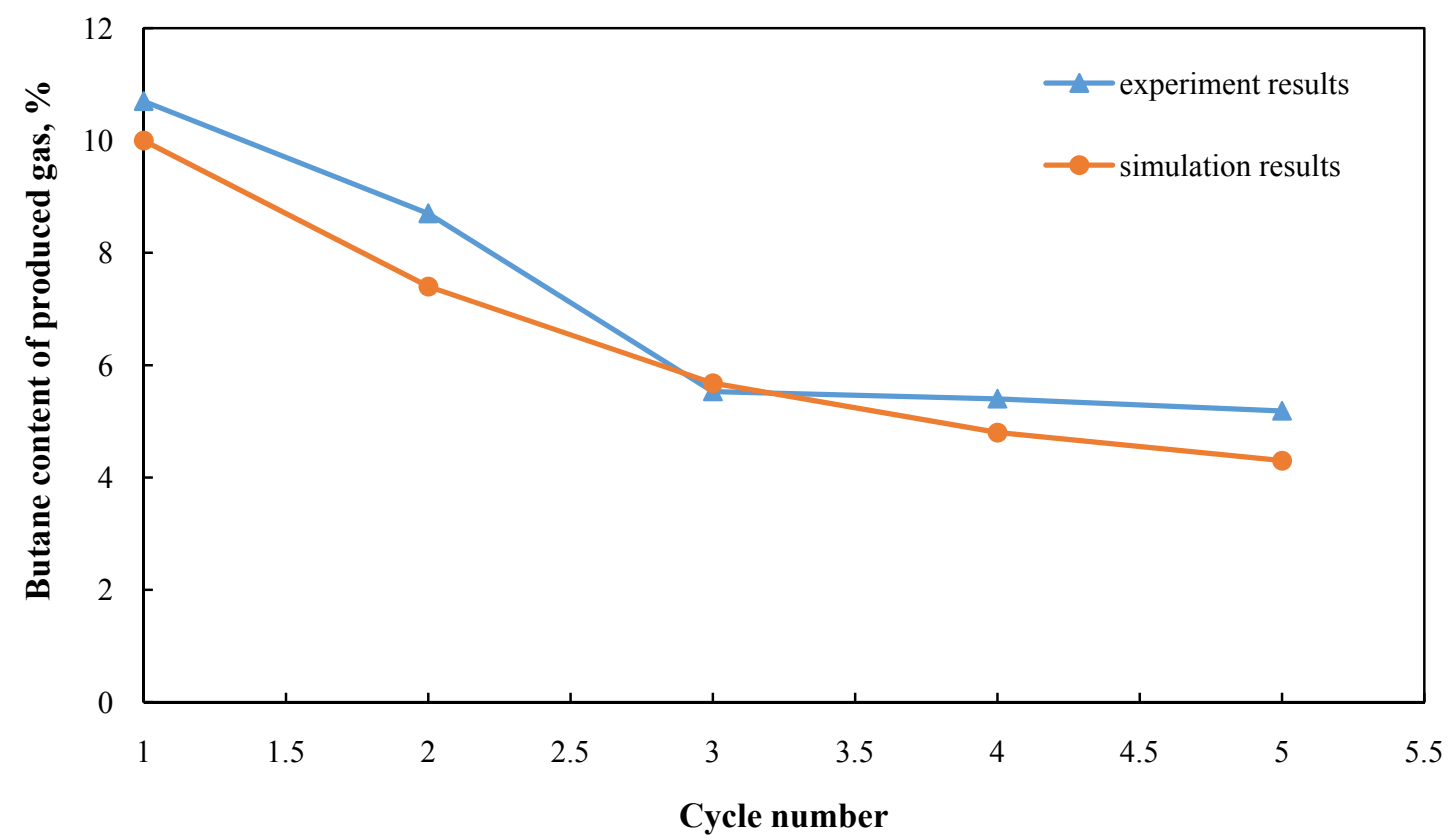

Fig. 14: Butane content comparison of simulation results with experimental data 
Since the simulation model was verified by the experimental results, the simulation could be applied for deeper study. Fig. 15 shows the butane content inthe produced gas in the simulation model whichdecreased with time as huff-n-puff gas injection cycles were applied.

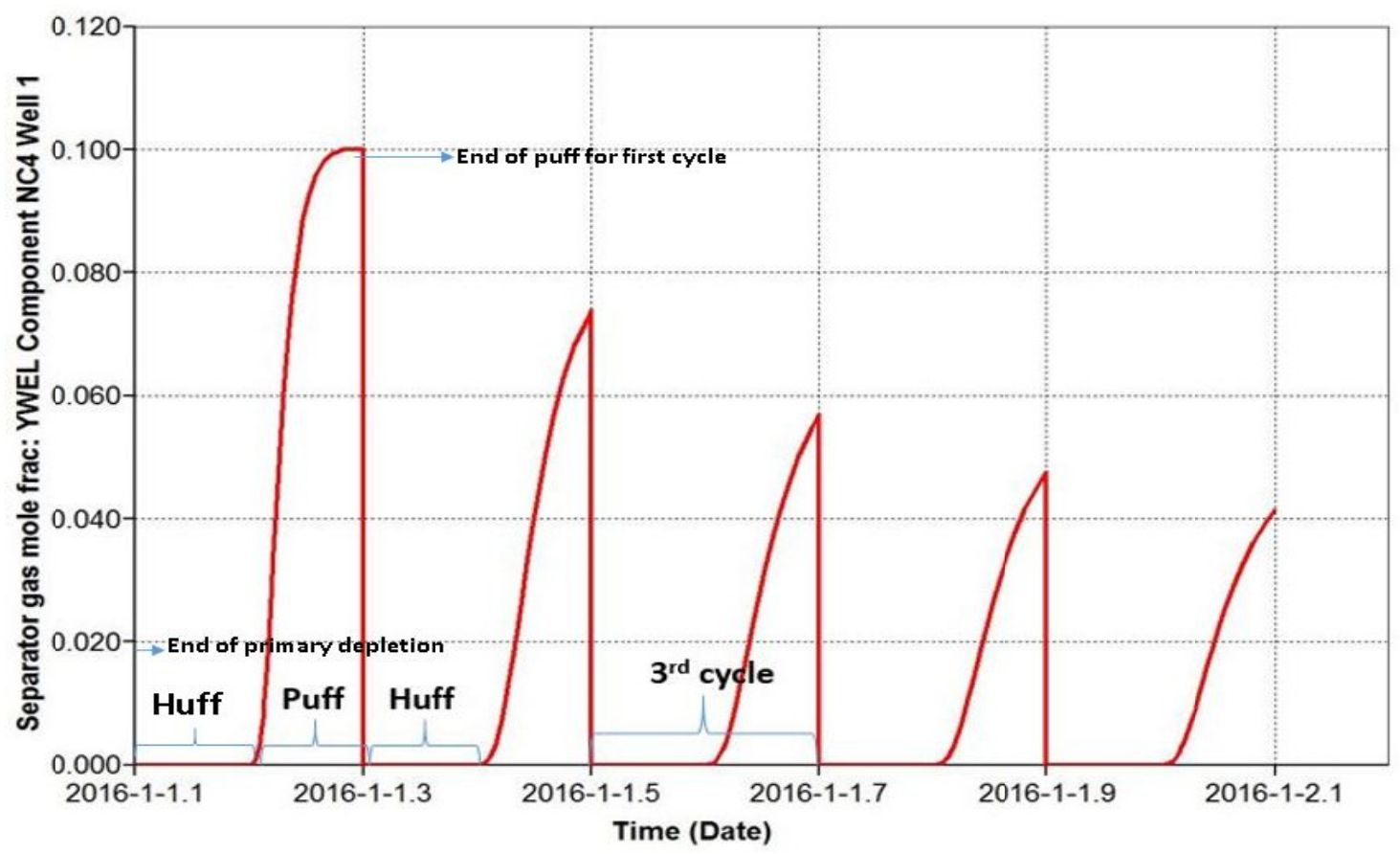

Fig. 15: Butane content in produced gas in simulation

As it mentioned before, the condensate accumulation reduces the relative permeability of gas. Fig. 16 shows the condensate saturation and gas relative permeability at three different time: beginning of primary depletion, end of primary depletion, end of huff process in $1^{\text {st }}$ cycle.AsFig. 16 shows, when the condensate was formed, the gas relative permeability was reduced. After the application of huff-n-puff gas injection, the pressure was increased and the condensate was re-vaporized to gas phase, and the gas relative permeability was restored.

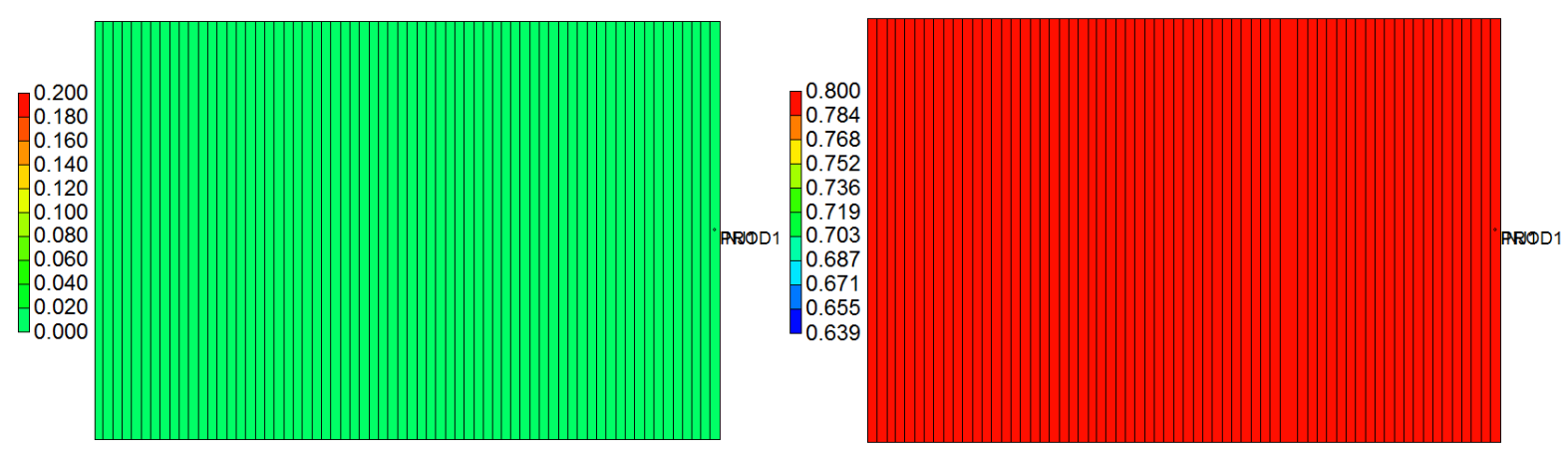

Condensate saturation at the beginning of primary depletion

Gas relative permeability at the beginning of primary depletion 


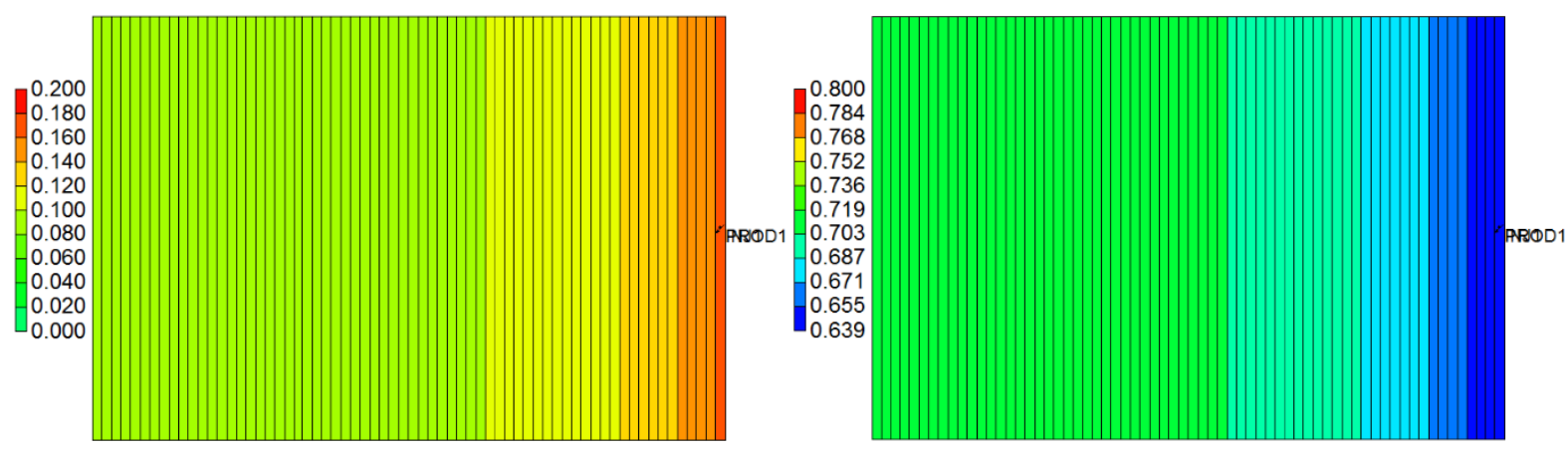

Condensate saturation at the end of primary depletion

Gas relative permeability at the end of primary depletion

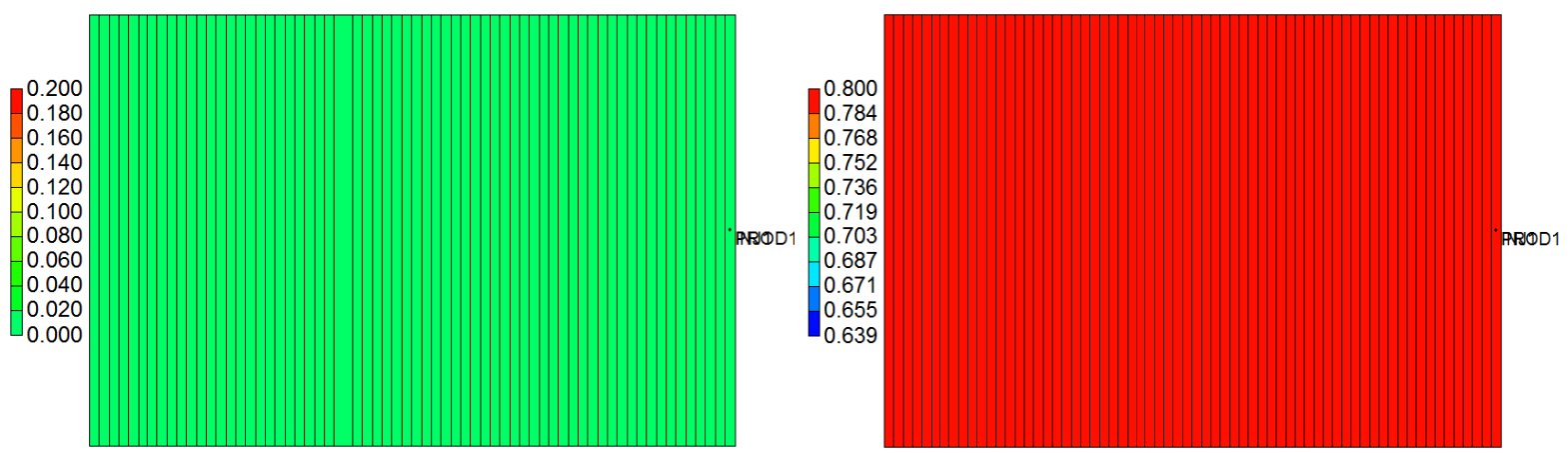

Condensate saturation at the end of huff process in $1^{\text {st }}$ cycle Gas relative permeability at the end of huff process in $1^{\text {st }}$ cycle

Fig. 16: condensate saturation and gas relative permeability at three different time

The production rate of gaseousbutane during the primary depletion process and huff-n-puff gas injection process is shown in Fig. 17. In the initial reservoir condition, because the pressure was higher than the dew point pressure, there was only gas phase, butane was in the gaseous state. Thus, in the beginning of primary depletion, the production of butane was very high. As the pressure was depleted lower than the dew point pressure,liquid butane was formed and accumulated in the core. Therefore, production of gaseous butane was reduced to almost 0.005 gmole/day in the later period of primary depletion as shown in Fig. 17.

After the primary depletion, huff-n-puff gas injection was applied. In the puff process of every cycle of huff-n-puff gas injection, gaseous butane was produced. During this period, the production rate of gaseous butane was increased and then decreased. Compared with the later period of the primary depletion, the production rate of gaseous butane in the first cycle was increased after the application of huff-n-puff. This indicates the incremental of the gaseous butane in the core. This is because in the huff process, condensate was re-vaporized into gas and was produced in the puff process. 


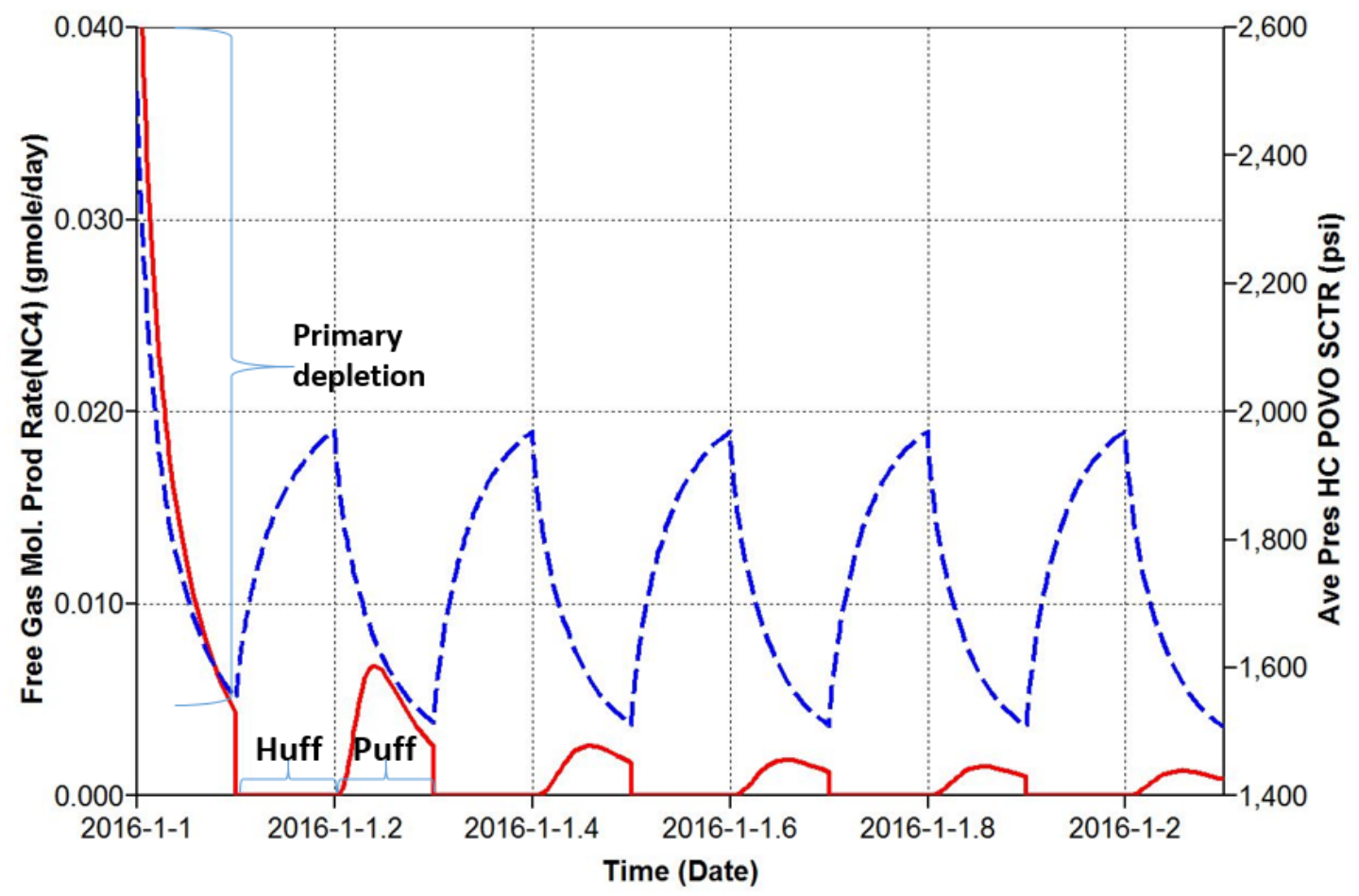

Free Gas Mol. Prod Rate(NC4) PROD1

Ave Pres HC POVO SCTR FIELD

Fig.17: Production rate of gaseous

It canalso be seen that in the period of huff-n-puff gas injection, the production rate of gaseous butane in the first cycle was higher than in the later ones. This was because after every cycle of huff-n-puff gas injection, less butane remained in the core. Thus, the production rate was reduced during the subsequent huff-n-puff gas injection as shown in Fig. 17. The Free Gas Mol PROD Rate (NC4) presents the gas-state butane production rate

Moreover, asshown in Fig. 18, in the beginning of primary depletion, there was very little liquid production, and this liquid was the condensate. And during the period of huff-n-puff gas injection, there was no liquid production from the well. However, the liquid condensate that remained in the reservoir was recovered, and the condensate (butane) content in the produced gas was increased. This indicates that the condensate was re-vaporized and produced as the gas state from the core. It proves the re-vaporization mechanism of huff-n-puff gas injection. 


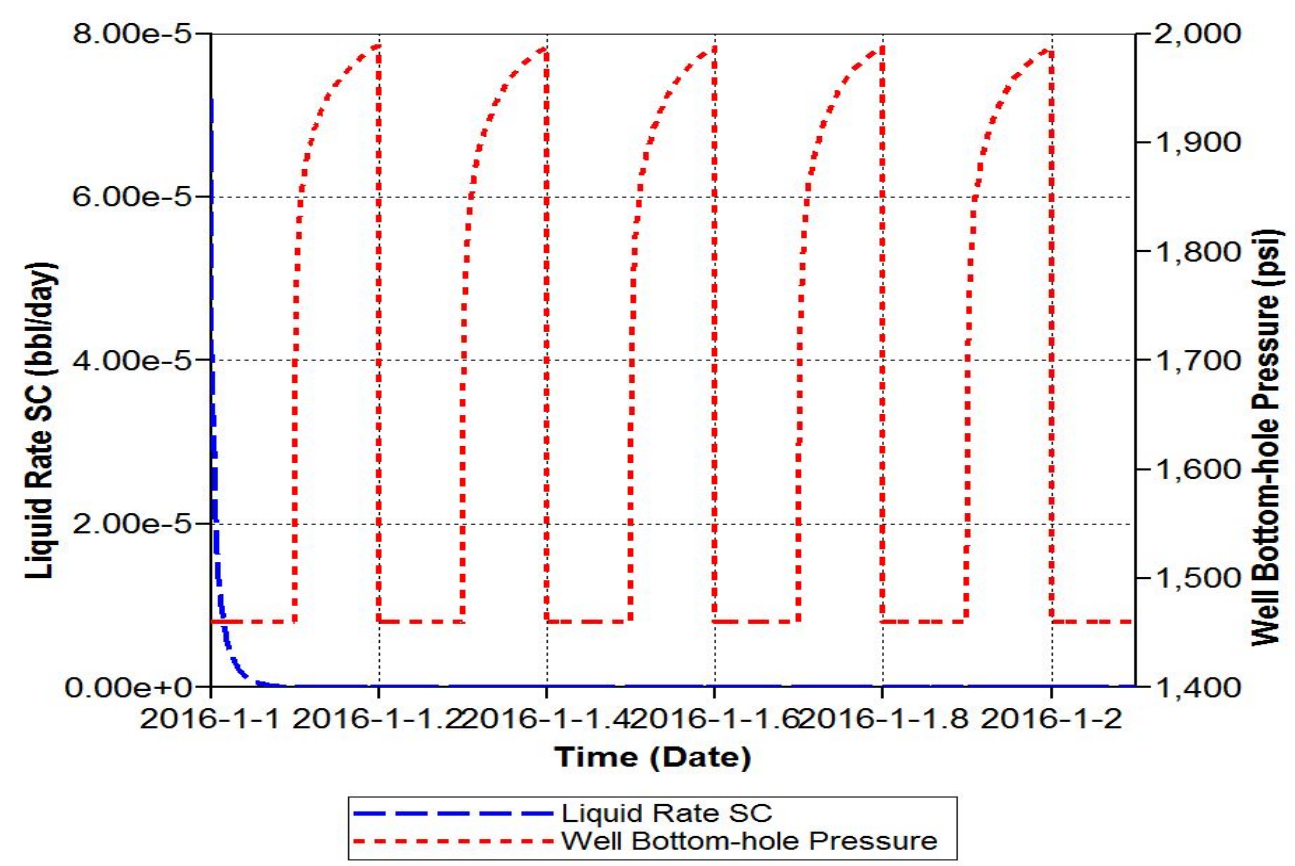

Fig. 18: Liquid production rate in simulation

Injected gas used in the huff-n-puff process was methane. And Fig. 19 shows the relationship between the injected volume of methane and the condensate recovery. As it can be seen, when the injected volume was $2.4 \mathrm{PV}$, the condensate recovery was 0.33 . As more methane was injected into the core during the huff process, more methane was produced during the puff process. Meanwhile, less butane was produced after every cycle. Thus, the methane produced during each puff period was relatively much higher than the butane produced, as shown in Fig. 20. It also shows that the butane fraction in the produced gas decreased with the cycle.This demonstrates that although more condensate was re-vaporized and produced asthe gas state, the fraction of the condensate in the produced gas was reduced.

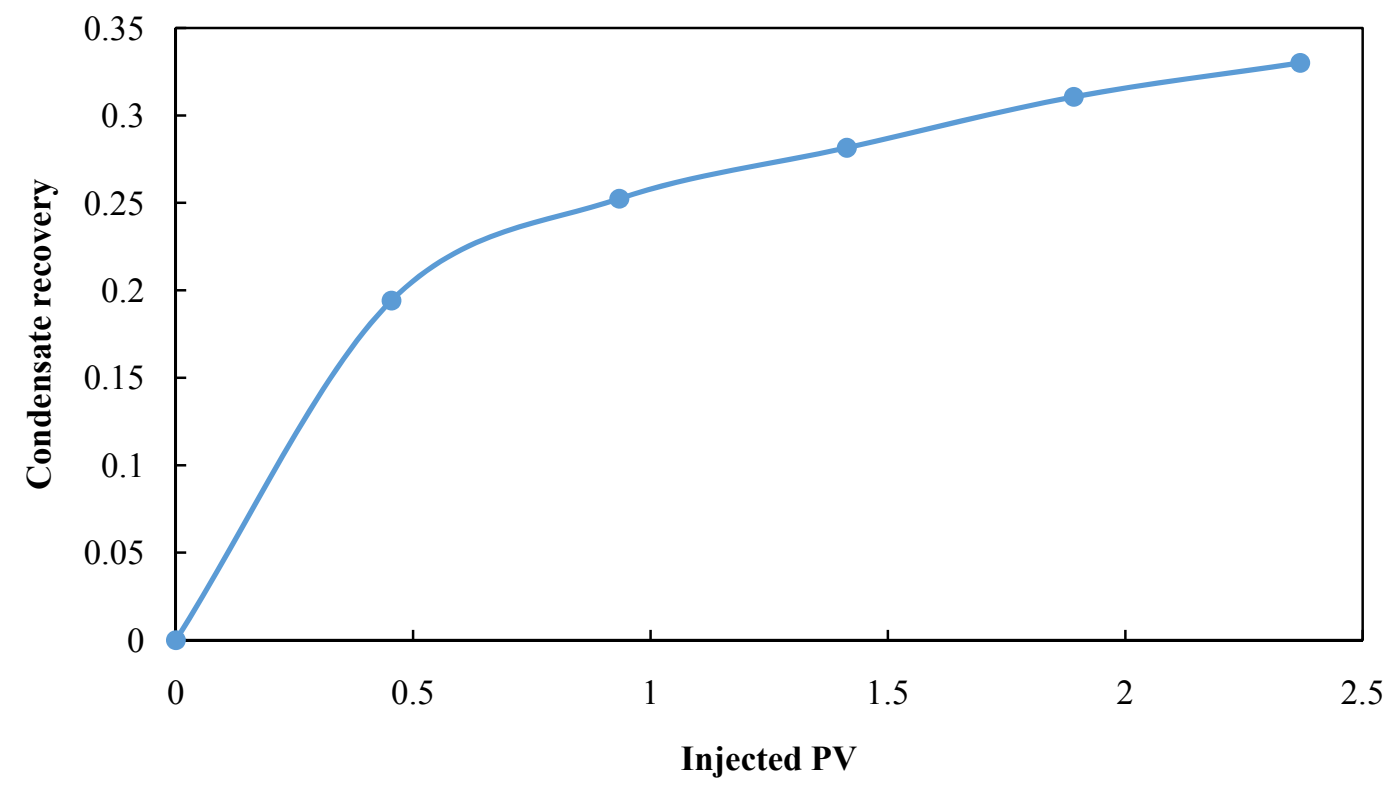

Fig. 19: Injected volume of methane vs.condensate recovery 


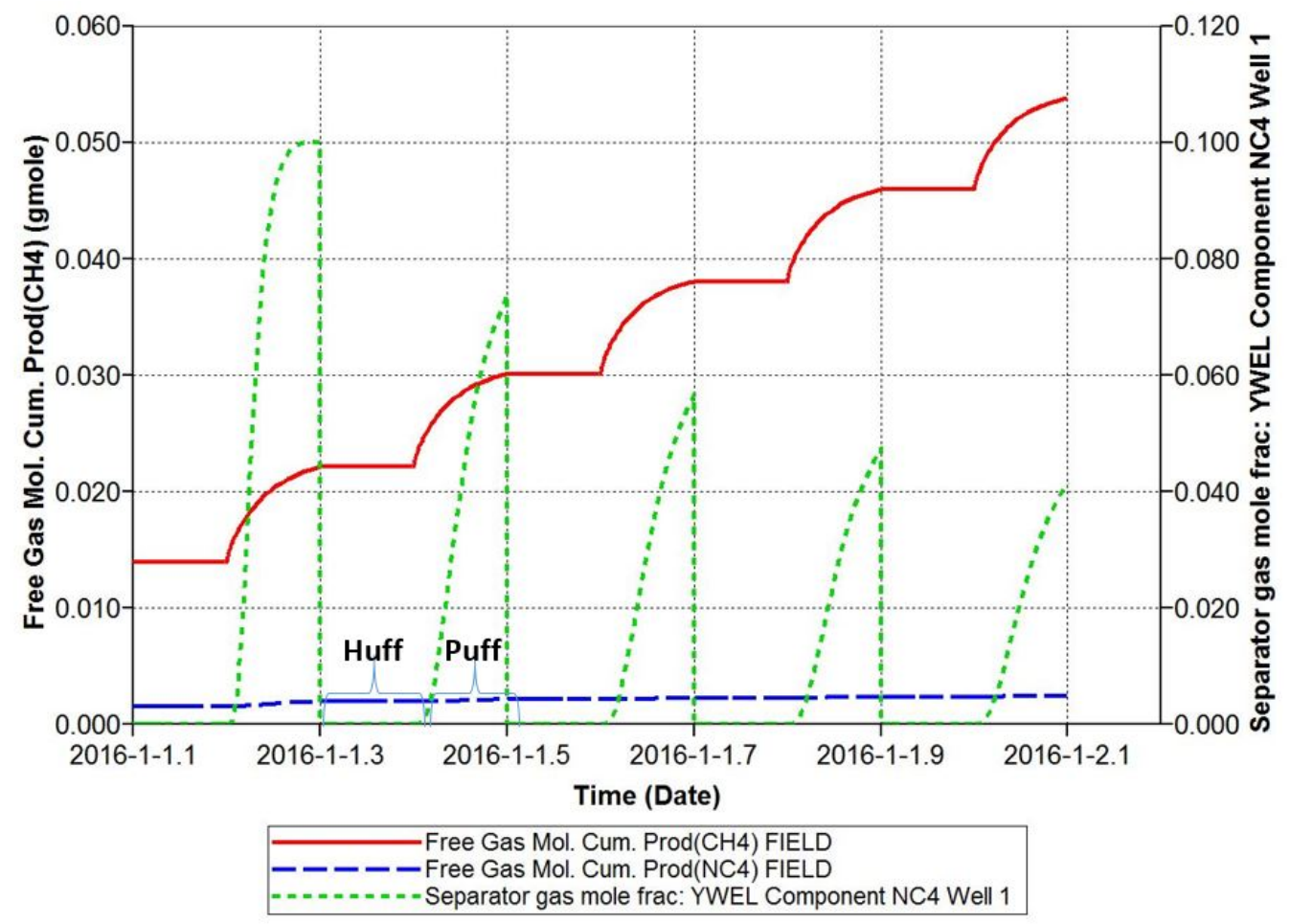

Fig.20: Comparison of cumulative production between methane and butane

\section{Conclusions}

We conducted experimental work and the experimental data was analyzed by simulation. Based on this study, we may draw the following conclusions.

(1) Both experiment and simulation workprove that huff-n-puff gas injection is an effective method to enhance condensate recovery in a shale core.

(2) The shale core-scale study shows that the main mechanism of huff-n-puff gas injection to enhance the condensate recovery is re-vaporization. When pressure is increased in the huff period,condensate is re-vaporized into the gas state and produced in the puff period.

(3) The fraction of the butane in the produced gas was reduced with the huff-n-puff cycle. This was because when methane was injected to increase the pressure in the huff period, more methane production was attained during the puff period. Meanwhile, butane was recovered after every cycle of huff-n-puff, less butaneremained in the core. Thus, although more butane was re-vaporized into the gas state and produced, the butane content in produced gas was reduced with the cycle.

\section{Acknowledgment}

The work presented in this paper is supported by the Department of Energy under Award Number DEFE0024311.

\section{References}


Abel, W., Jackson, R. F., Wattenbarger, R. A., 1970. Simulation of a Partial Pressure Maintenance Gas Cycling Project with a Compositional Model, Carson Creek Field, Alberta. J. Pet. Technol. 22 (1), $38-46$.

Ahmed, T., Evans, J., Kwan, R., Vivian, T., 1998. Wellbore Liquid Blockage in Gas-Condensate Reservoirs. In: Paper SPE 51050 presented at SPE Eastern Region Meeting, Pittsburgh, Pennsylvania, USA, 9-11 November.

Al-Anazi, H. A., Pope, G. A., Sharma, M. M., Metcalfe, R. S., 2002. Laboratory Measurements of Condensate Blocking and Treatment for Both Low and High Permeability Rocks. In: Paper SPE 77546 presented at SPE Annual Technical Conference and Exhibition, San Antonio, Texas, USA, 29 September-2 October.

Al-Anazi, H.A., Walker, J.G., Pope, G.A., Sharma, M.M., 2005. A Successful Methanol Treatment in a Gas Condensate Reservoir: Field Application. In:Paper SPE 80901 presentedat SPE Production and Operations Symposium, Oklahoma City, Oklahoma, USA, 23-26 March.

Amini, S., Aminshahidy, B., Afshar, M., 2011. Simulation Study of Enhanced Condensate Recovery in a Gas-Condensate Reservoir. Iranian J. Chem. Eng. 8(1), 3-14.

Bang, V. S. S., Yuan, C., Pope, G. A., Sharma, M. M., Baran, J. R., Skildum, J., Linnemeyer, H. C., 2008. Improving Productivity of Hydraulically Fractured Gas Condensate Wells by Chemical Treatment. In: Paper OTC 19599 presented at Offshore Technology Conference, Houston, Texas, USA, 5-8 May.

Bang, V. S. S., Pope, G. A., Sharma, M. M., Baran, J. R., 2009. Development of a Successful Chemical Treatment for Gas Wells with Liquid Blocking. In: Paper SPE 124977 presented at SPE Annual Technical Conference and Exhibition, New Orleans, Louisiana, USA, 4-7 October.

Du, L., Walker, J. G., Pope, G. A., Sharma, M. M., Wang, P., 2000. Use of Solvents to Improve the Productivity of Gas Condensate Wells. In: Paper SPE 62935 presented at SPE Annual Technical Conference and Exhibition, Dallas, Texas, USA, 1-4 October.

Kumar, V., Pope, G. A., Sharma, M. M., 2006. Improving the Gas and Condensate Relative Permeability Using Chemical Treatments. In: Paper SPE 100529 presented at SPE Gas Technology Symposium, Calgary, Alberta, Canada, 15-17 May.

Luo, K., Li, S., Zheng, X., Chen, G., Dai, Z.,Liu, N., 2001. Experimental Investigation into Revaporization of Retrograde Condensate by Lean Gas Injection.In: Paper SPE 68683 presented at SPE Asia Pacific Oil and Gas Conference and Exhibition, Jakarta, Indonesia, 17-19 April.

Marir, B. and Tiab, D., 2006. Performance of Horizontal Wells in Gas Condensate Reservoirs: Hassi R'Mel, Algeria. In: Paper SPE 100753 presented at SPE Russian Oil and Gas Technical Conference and Exhibition, Moscow, Russia, 3-6 October.

Meng, X., Sheng, J. J., 2015. Simulation Study on Huff-n-Puff Gas Injection to Enhance Condensate Recovery in Fractured Shale Gas Reservoir. In: Paper 431948 presented at 2015 AIChE Annual Meeting, Salt Lake City, Utah, USA, 3-13 November, 2015.

Sanger, P. J., Hagoort, J., 1998. Recovery of Gas-Condensate by Nitrogen Injection Compared with Methane Injection. SPE J. 3(1), 26-33.

Sheng, J. J., 2015. Increase Liquid Oil Production by Huff-n-Puff of Produced Gas in Shale Gas Condensate Reservoirs. J. Nat. Gas Sci. Eng. 11, 19-26.

Vo, H. X. 2010. Composition Variation during Flow of Gas-Condensate Wells. MS thesis, Stanford University, Stanford, California, September 2010.

Zheng, Y., Rao, D. N., 2010. Surfactant-Induced Spreading and Wettability Effects in Condensate Reservoirs. In: Paper SPE 129668 presented at SPE Improved Oil Recovery Symposium, Tulsa, Oklahoma, USA, 24-28 April.

Zheng, Y., Rao, D. N., 2011. Experimental Study of Spreading and Wettability Effects by Surfactants in Condensate Reservoirs at Reservoir Conditions. In: Paper SPE 141016 presented at SPE International 
Symposium on Oilfield Chemistry, The Woodlands, Texas, USA, 11-13 April. 